\title{
The Relationship of Insulin Resistance With SNP 276G > T at Adiponectin Gene and Plasma Long-Chain Polyunsaturated Fatty Acids in Obese Children
}

\author{
ELVIRA VERDUCI, SILVIA SCAGLIONI, CARLO AGOSTONI, GIOVANNI RADAELLI, MARIALUISA BIONDI, ANA S. MANSO,
} ENRICA RIVA, AND MARCELLO GIOVANNINI

\begin{abstract}
Departments of Pediatrics [E.V., S.S., C.A., G.R., E.R., M.G.] and Clinical Chemistry and Microbiology [M.B.], University of Milan, I-20142 Milan, Italy; Chemical and Biological Engineering Department [A.S.M.], Instituto Superior Técnico, 1049-001 Lisbon, Portugal
\end{abstract}

\begin{abstract}
This study examined the association of insulin resistance with single-nucleotide polymorphism (SNP) $276 \mathrm{G}>\mathrm{T}$ at adiponectin gene and the plasma long-chain polyunsaturated fatty acids (LCPUFAs) profile in obese children. One hundred thirty-one normolipidaemic obese children aged $8-13$ y (53 girls and 68 boys) entered the study. The prevalence of T allele carriers at SNP276 was $48.8 \%$. Mean [SD] values of fasting insulin and homeostasis model assessment-insulin resistance (HOMA-IR) index in noncarriers versus carriers of T allele were 12.4 [6.4] versus $20.6[6.3] \mu \mathrm{U} / \mathrm{mL}(p=0.039)$ and $2.6[1.4]$ versus $4.5[1.7](p=0.032)$. Mean [SD] values of plasma C18:3n - 3, C20:5n - 3/C20:4n - 6, and $n-6 / n-3$ LCPUFA in phospholipids in noncarriers versus carriers of $\mathrm{T}$ allele were 0.10 [0.04] versus 0.08 [0.03] \% ( $p=0.013), 0.04$ [0.01] versus $0.03[0.01] \%(p=0.045)$, and $4.4[0.7]$ versus $4.9[0.9] \%(p=$ $0.005)$, respectively. Insulin resistance was independently associated with SNP $276 \mathrm{G}>\mathrm{T}(p=0.002)$ and $n-6 / n-3$ LCPUFA $(p=$ 0.042 ) in plasma phospholipids, and interaction was found between SNP $276 \mathrm{G}>\mathrm{T}$ and $n-6 / n-3$ LCPUFA $(p=0.046)$. These findings suggest that obese children carriers of the SNP $276 \mathrm{G}>\mathrm{T}$ may be at increased risk of metabolic complications compared with noncarriers, possibly due in part to a different plasma phospholipids profile. (Pediatr Res 66: 346-349, 2009)
\end{abstract}

$I^{\mathrm{n} m}$ nsulin resistance is a major component of the metabolic syndrome (1), prevalent among children and adolescents with obesity (2), that is a risk condition for the development of early morbidity (3). The mechanisms underlying insulin resistance have not been fully elucidated but genetic and environmental factors may affect its etiology (4). Genes involved in adipose tissue metabolism may be responsible for insulin sensitivity (4), and cytokines produced by adipose tissue may influence the lipid metabolism $(5,6)$. In particular, adiponectin may contribute to modulate insulin sensitivity $(7,8)$. Different single-nucleotide polymorphisms (SNPs) have been localized in the adiponectin gene (adipocyte, $\mathrm{C} 1 \mathrm{q}$, and collagen domain containing $[A C D C])(9)$. The most common reported variants are the substitution of $\mathrm{T}$ to $\mathrm{G}$ in exon $2(45 \mathrm{~T}>\mathrm{G})$ and of $\mathrm{G}$ to $\mathrm{T}$ substitution in intron $2(276 \mathrm{G}>\mathrm{T})$, which may be related to glucose intolerance and type 2 diabetes in adults (10-14). A recent study showed that insulin resistance and risk of cardio-

Received February 11, 2009; accepted April 21, 2009

Correspondence: Elvira Verduci, M.D., Department of Pediatrics, San Paolo Hospital, University of Milan, Via A di Rudinì 8, I-20142 Milan, Italy; e-mail: elvira.verduci@unimi.it vascular disease are more strongly associated with SNP $276 \mathrm{G}>\mathrm{T}$ than $\mathrm{SNP} 45 \mathrm{~T}>\mathrm{G}$ in men (15). In obese children, adiponectin gene may be a determinant in modulating insulin sensitivity (16).

Quality of dietary fats might be also related to the metabolic syndrome (17). Flachs et al. (18) showed in animals that dietary $n-3$ long-chain polyunsaturated fatty acids (LCPUFAs) might stimulate the expression of the gene encoding adiponectin $(A C D C)$ and additionally improve the insulin resistance. A recent study found a decrease in adiponectin levels in overweight adults supplemented with $n-3$ polyunsaturated fatty acids (PUFA) compared with unsupplemented subjects, with the greatest decrease among those carrying the SNP 276G $>$ T (19).

Despite the potential clinical and practical relevance, there is lack of studies evaluating the mutual relationship of insulin resistance with SNP 276G $>$ T and LCPUFAs in the pediatric population. This study assessed whether an association may exist of insulin resistance with SNP $276 \mathrm{G}>\mathrm{T}$ at adiponectin gene and plasma LCPUFAs in normolipidic obese children.

\section{MATERIALS AND METHODS}

This cross-sectional observational study examined 131 obese children aged $8-13$ y (53 girls and 68 boys), consecutively admitted to our department from January 2006 to September 2008. Inclusion criteria were as follows: weight at birth $\geq 2500$ g, gestational age 37-42 wk inclusive, singleton birth, obesity, and having white parents. Children exhibiting diabetes mellitus and/or endocrine diseases, chronic liver diseases, and/or hyperlipidemia, according to Italian guidelines (20), were excluded to prevent possible bias effects on plasma fatty acid status (21).

A pediatrician described the investigation and written informed consent was obtained from the parents or the legal guardian. The Ethical Committee of the San Paolo Hospital, Milan, approved the study.

Anthropometrics (height, weight), blood pressure, fasting biochemical variables (glucose, insulin, lipid, and fatty acids) of children were evaluated within $48 \mathrm{~h}$ of hospital admission. Two experienced pediatricians, according to standardized procedures, performed all anthropometric measurements. The body weight $(\mathrm{kg})$ was measured with an electronic scale accurate to $0.1 \mathrm{~kg}$ and height $(\mathrm{cm})$ was measured to the nearest $0.5 \mathrm{~cm}$ with a Harpenden stadiometer. For each anthropometric variable, three measurements were taken and the mean value was considered for the analysis. The coefficient of variation of the measurements ranged from 0.7 to $1.5 \%$ (observer 1 ) and from 0.8 to $1.5 \%$

Abbreviations: ACDC, adipocyte, $\mathrm{C1q}$, and collagen domain containing; FAs, fatty acids; HOMA, homeostatic model assessment; LCPUFAs, longchain polyunsaturated fatty acids; PUFAs, polyunsaturated fatty acids; SNPs, single-nucleotide polymorphisms 
(observer 2). The small intraobserver variation and comparable interobservers variation were deemed to yield reliable anthropometric data. The body mass index (BMI) was calculated from the ratio of weight to height (2) $\left(\mathrm{kg} / \mathrm{m}^{2}\right)$.

In accordance with the International Obesity Task Force, a child was defined obese if her/his BMI was above the age- and sex-adjusted BMI Cole's curve passing through the cutoff of $30 \mathrm{~kg} / \mathrm{m}^{2}$ at $18 \mathrm{y}$ (22). Compared with Italian age- and sex-adjusted growth charts for BMI (23), all participating children exhibited BMI above the 97th percentile. BMI $z$-scores were calculated and adjusted for age and gender by using the LMS-method of Cole (24) and Italian reference data (23). The same pediatrician performed the Tanner staging of puberty.

Fasting blood samples were taken in the morning at $8 \mathrm{~h} \pm 30 \mathrm{~min}$. Flavored glucose at a dose of $1.75 \mathrm{~g} / \mathrm{kg}$ body weight (up to a maximum of $75 \mathrm{~g}$ ) was then given orally, and additional blood samples were taken for measurements of plasma glucose at $120 \mathrm{~min}$. Blood samples were collected and analyzed immediately at the Hospital Department of Biochemistry. Serum insulin levels $(\mu \mathrm{U} / \mathrm{mL})$ were determined by a electrochemilluminescence immune assay analyzer, and plasma glucose levels $(\mathrm{mg} / \mathrm{dL})$ by enzymatic method. Insulin resistance (IR) was estimated by the homeostatic model assessment (HOMA) (25). HOMA-IR index is calculated as the product of fasting glucose $(\mathrm{mmol} / \mathrm{L})$ and fasting insulin $(\mu \mathrm{U} / \mathrm{mL})$, divided by $22.5(25)$. Fasting total cholesterol (TC) and triacylglycerol (TG) plasma levels were measured using a dry multiplayer enzymatic method (Ectachem DT-60; Eastman Kodak Co., Rochester, NY). LDL-cholesterol (LDL-C) serum levels were calculated according to the Friedewald formula (LDL-C $=$ TC [HDL-C + TG/5]) (26). The SI conversion factors used in study were to convert glucose to $\mathrm{mg} / \mathrm{dL}$, divide values by 0.0555 ; to convert cholesterol, divide values by 0.0259 ; to convert triglycerides, divide values by 0.0113 .

Plasma fatty acid (FA) analyses (expressed as \% total FAs) were performed by means of capillary gas chromatography after lipid extraction according to Folch et al. (27) and the phospholipid (PL) fraction was separated by thin-layer chromatography (28).

Serum adiponectin levels were determined by RIA (LINCO Research Inc., St. Louis, MO).

The blood pressure was measured by the same investigator using a validated protocol (29). Systolic blood pressure and diastolic blood pressure were measured at morning twice at the right arm after a 10-min rest in the supine position using a calibrated sphygmomanometer and averaged. The cuff size, which was based on the length and circumference of the upper arm, was chosen to be as large as possible without having the elbow skin crease obstructing the stethoscope (29).

Lastly, a medical history was collected from parents by a standardized questionnaire at a personal interview conducted by the same pediatrician before the child's hospital discharge. Additionally, dietary habits of children were assessed by means of an age-adjusted Food Frequency Questionnaire made up of 116 items and designed according to Block et al. (30). The same experienced dietician, unaware of the obesity status of children, interviewed mothers for $\sim 50 \mathrm{~min}$, and each meal was analyzed to find out which food was eaten and how often. Usual portion sizes were estimated using household measures, the weight of purchase (e.g. pasta) or unit (e.g. fruit juice). A 24-h recall on the day before the hospital admission was further recorded at the end of the interview to standardize the usual serving size. Quantification and analysis of the energy intake and nutrient composition were performed with an ad hoc PC software program developed at our department and based on the Food and Nutrient Data Base issued by the National Institute of Nutrition (31).

Genotyping. SNP 276G $>\mathrm{T}$ at adiponectin gene was considered given its high prevalence in the general population (13) and the recognized association with glucose intolerance and type 2 diabetes in adults (10-15). The genomic DNA was extracted in the whole-blood samples using a QIAamp DNA Blood Mini Kit (Qiagen, Valencia, CA). The Polymerase Chain Reaction (PCR) amplification was performed in a total volume of $20 \mu \mathrm{L}$ containing the PCR buffer $(10 \times$ Optiperform Buffer III of $40 \mathrm{mM} \mathrm{KCl}, 10 \mathrm{mM}$ Tris- $\mathrm{HCl}, 1.5 \mathrm{mM}$ $\mathrm{MgCl} 2), 45 \mathrm{ng} / \mu \mathrm{L}$ genomic DNA, 1 unit of TaqDNA polymerase, $250 \mu \mathrm{M}$ concentrations each dNTPs, and 10 pmol of the sense and antisense primers. PCR products were genotyped by sequencing with an ABI Prism 3100 Genetic Analyzer (Applied Biosystems, Foster City, CA).

Sample size. The sample size was determined to detect a mean difference in insulin resistance between children with or without SNP $276 \mathrm{G}>\mathrm{T}$ at adiponectin gene of $0.5 \mathrm{SD}$ or more. With an accepted type I error level of 5\% and a power of $80 \%$, at least 64 children were required in each group. As the expected prevalence of SNP $276 \mathrm{G}>\mathrm{T}$ would be $\sim 49 \%$ (13), a total of at least 131 children needed to be recruited.

Statistical analysis. Descriptive data are shown as mean (SD) or number of observations (percentage). Comparison between the groups for continuous variables was performed by the $t$ test for unpaired data or the Mann-Whitney test, as appropriate. The $\chi^{2}$ test was used for comparing discrete variables. Triacylglycerol, insulin, and HOMA-IR were not normally distributed, and $\log _{10}$-transformation was used for analysis. For clarity of interpretation, results are expressed as untransformed values. Adjustments were made for potential confounders (gender, age, body weight at birth, BMI $z$-score, duration of obesity and Tanner stage, plasma total cholesterol and triacylglycerol). Additionally, association of insulin resistance with the SNP 276G $>$ T and fatty acids was assessed by an ANOVA model including $\log _{10}$ HOMA-IR as dependent variable, SNP $276 \mathrm{G}>\mathrm{T}$ as factor, and fatty acids as covariates, also adjusting for confounders. Interaction between the SNP $276 \mathrm{G}>\mathrm{T}$ and fatty acids was further tested. All $p$-values less than 0.05 were considered to indicate statistical significance (two-tailed test). The SPSS software, version 15.0 (SPSS Inc, Chicago, IL) was used for all the statistical analysis.

\section{RESULTS}

In the studied sample, the prevalence of $\mathrm{T}$ allele carriers at SNP276 was $48.8 \%$ (GG 51.2\%, GT 38.8\%, TT 9.9\%). The distribution of Tanner stage did not differ between carriers and noncarriers of SNP $276 \mathrm{G}>\mathrm{T}$ : stage I, 49.1 versus $56.1 \%$; stage II-III, 37.7 versus $36.9 \%$; stage IV-V, 7.0 versus $13.2 \%$, respectively. Table 1 reports the characteristics of children at recruitment according to SNP 276G $>$ T genotype. Carriers of $\mathrm{T}$ allele showed higher fasting insulin levels (mean difference, $\Delta, 8.2 ; \mu \mathrm{U} / \mathrm{mL} 95 \% \mathrm{CI}, 1.6$ to 14.9$)$ and higher HOMA-IR ( $\Delta$, $1.9 ; 95 \%$ CI, 0.3 to 3.5 ) than GG homozygotes. Significance of association of SNP $276 \mathrm{G}>\mathrm{T}$ with BMI $z$-score was borderline $(\Delta, 0.12 ; 95 \% \mathrm{CI},-0.01$ to 0.26$)$. No difference was found between the groups for any other trait listed in Table 1 . Association of SNP 276G $>$ T with fasting insulin levels and HOMA-IR remained significant also after adjusting for confounders. Compared with GG homozygotes, children with

Table 1. Characteristics of children at hospital admission according to adiponectin SNP 276G>T

\begin{tabular}{lccc}
\hline \multicolumn{1}{c}{ Variable } & $\begin{array}{c}\text { SNP } 276 \mathrm{G}>\mathrm{T} \\
\text { carriers }(n=64)\end{array}$ & $\begin{array}{c}\text { Noncarriers } \\
(n=67)\end{array}$ & $p^{*}$ \\
\hline Sex (boy/girl) & $32 / 27$ & $36 / 26$ & 0.684 \\
Age (y) & $10.2 \pm 1.8$ & $10.0 \pm 1.7$ & 0.400 \\
BMI z-score & $2.28 \pm 0.36$ & $2.16 \pm 0.37$ & 0.066 \\
Duration of obesity (y) & $4.3 \pm 2.3$ & $4.3 \pm 2.3$ & 0.889 \\
Sistolic blood pressure & $111 \pm 12$ & $109 \pm 11$ & 0.921 \\
$\quad$ (mm Hg) & & & \\
Diastolic blood & $67 \pm 7$ & $68 \pm 8$ & 0.838 \\
$\quad$ pressure (mm Hg) & & & \\
Fasting plasma glucose & $87.7 \pm 9.8$ & $85.8 \pm 6.1$ & 0.774 \\
t0 (mmol/L) & & & \\
Plasma glucose at t120 & $103.5 \pm 17.1$ & $104.5 \pm 18.0$ & 0.879 \\
$\quad(\mathrm{mmol} / \mathrm{L})$ & & & \\
Fasting insulin level & $20.6 \pm 6.3$ & $12.4 \pm 6.4$ & $0.039 \dagger$ \\
$\quad(\mu \mathrm{U} / \mathrm{mL})$ & & & \\
HOMA-IR & $4.5 \pm 1.7$ & $2.6 \pm 1.4$ & $0.032 \dagger$ \\
Total cholesterol & $169.5 \pm 25.9$ & $168.6 \pm 30.0$ & 0.815 \\
$\quad(\mathrm{mg} / \mathrm{dL})$ & & & \\
HDL (mg/dL) & $49.6 \pm 11.0$ & $50.8 \pm 13.4$ & 0.661 \\
LDL (mg/dL) & $96.4 \pm 24.6$ & $97.1 \pm 30.0$ & 0.853 \\
LDL/HDL & $2.0 \pm 0.6$ & $2.0 \pm 0.8$ & 0.965 \\
Triacylglycerols & $107.7 \pm 53.1$ & $104.1 \pm 59.5$ & 0.527 \\
$\quad(\mathrm{mg} / \mathrm{dL})$ & & & \\
Adiponectin level & $18.4 \pm 9.2$ & $18.5 \pm 8.3$ & 0.835 \\
$\quad(\mathrm{ng} / \mathrm{mL})$ & & & \\
\hline & & &
\end{tabular}

Values are mean \pm SD or number of observations.

* The $p$-values related to blood pressure and biochemical variable are adjusted for gender, age, body weight at birth, BMI $z$-score, duration of obesity and Tanner stage.

$\dagger$ Statistically significant. 
Table 2. LCPUFA as FA \% of plasma total lipids and plasma phospholipids according to adiponectin SNP 276G>T

\begin{tabular}{|c|c|c|c|c|c|c|}
\hline \multirow[b]{3}{*}{ Variable } & \multicolumn{6}{|c|}{ FA $\%$} \\
\hline & \multicolumn{3}{|c|}{ Plasma total lipids } & \multicolumn{3}{|c|}{ Plasma phospholipids } \\
\hline & $\begin{array}{c}\text { SNP } 276 \mathrm{G}>\mathrm{T} \text { carriers } \\
(n=64)\end{array}$ & $\begin{array}{l}\text { Noncarriers } \\
\quad(n=67)\end{array}$ & $p^{*}$ & $\begin{array}{c}\text { SNP 276G }>\text { T carriers } \\
(n=64)\end{array}$ & $\begin{array}{l}\text { Noncarriers } \\
\quad(n=67)\end{array}$ & $p^{*}$ \\
\hline Saturated FA & $36.2 \pm 2.3$ & $35.3 \pm 2.2$ & 0.145 & $48.3 \pm 3.8$ & $48.5 \pm 2.2$ & 0.835 \\
\hline Monounsaturated FA & $25.9 \pm 2.6$ & $27.2 \pm 3.2$ & $0.014 \dagger$ & $17.7 \pm 3.0$ & $16.7 \pm 2.6$ & 0.263 \\
\hline Polyunsaturated FA & $37.9 \pm 3.5$ & $37.4 \pm 4.3$ & 0.240 & $34.0 \pm 3.5$ & $34.7 \pm 3.6$ & 0.420 \\
\hline $\mathrm{n}-6$ PUFA & $35.2 \pm 3.3$ & $34.7 \pm 4.2$ & 0.231 & $31.0 \pm 2.8$ & $31.6 \pm 3.3$ & 0.473 \\
\hline $\mathrm{n}-3$ PUFA & $2.5 \pm 0.6$ & $2.6 \pm 0.6$ & 0.960 & $2.8 \pm 0.9$ & $3.0 \pm 0.7$ & 0.365 \\
\hline$n-6 / n-3$ PUFA & $14.5 \pm 3.1$ & $14.3 \pm 3.5$ & 0.657 & $12.1 \pm 3.4$ & $11.1 \pm 2.7$ & 0.307 \\
\hline $\mathrm{n}-6$ LCPUFA & $10.1 \pm 1.4$ & $9.3 \pm 1.7$ & $0.010 \dagger$ & $12.8 \pm 2.7$ & $12.7 \pm 2.1$ & 0.718 \\
\hline $\mathrm{n}-3$ LCPUFA & $2.3 \pm 0.6$ & $2.2 \pm 0.6$ & 0.645 & $2.7 \pm 0.9$ & $3.0 \pm 0.6$ & 0.211 \\
\hline$n-6 / n-3$ LCPUFA & $4.6 \pm 1.0$ & $4.4 \pm 1.0$ & 0.202 & $4.9 \pm 0.9$ & $4.4 \pm 0.7$ & $0.005 \dagger$ \\
\hline$C 18: 2 n-6$ & $25.1 \pm 3.0$ & $25.4 \pm 3.7$ & 0.955 & $18.2 \pm 1.8$ & $18.9 \pm 2.5$ & 0.412 \\
\hline$C 20: 4 n-6$ & $7.2 \pm 1.1$ & $6.6 \pm 1.3$ & $0.005 \dagger$ & $8.7 \pm 2.1$ & $8.5 \pm 1.8$ & 0.876 \\
\hline$C 18: 3 n-3$ & $0.26 \pm 0.09$ & $0.33 \pm 0.12$ & $0.007 \dagger$ & $0.08 \pm 0.03$ & $0.10 \pm 0.04$ & $0.013 \dagger$ \\
\hline$C 20: 5 n-3$ & $0.43 \pm 0.19$ & $0.44 \pm 0.15$ & 0.658 & $0.31 \pm 0.1$ & $0.34 \pm 0.11$ & 0.254 \\
\hline$C 22: 6 n-3$ & $1.5 \pm 0.5$ & $1.4 \pm 0.5$ & 0.913 & $1.94 \pm 0.70$ & $2.05 \pm 0.55$ & 0.595 \\
\hline$C 20: 3 n-9$ & $0.16 \pm 0.08$ & $0.15 \pm 0.08$ & 0.560 & $0.16 \pm 0.08$ & $0.15 \pm 0.05$ & 0.875 \\
\hline$C 20: 5 n-3 / C 20: 4 n-6$ & $0.06 \pm 0.02$ & $0.07 \pm 0.02$ & $0.043 \dagger$ & $0.03 \pm 0.01$ & $0.04 \pm 0.01$ & $0.045 \dagger$ \\
\hline$C 22: 6 n-3 / C 20: 4 n-6$ & $0.21 \pm 0.06$ & $0.22 \pm 0.07$ & 0.396 & $0.22 \pm 0.06$ & $0.24 \pm 0.05$ & 0.087 \\
\hline
\end{tabular}

Values are mean \pm SD.

* The $p$-values adjusted for gender, age, body weight at birth, BMI $z$-score, duration of obesity and Tanner stage, plasma total cholesterol, and triacylglycerol concentrations.

$\dagger$ Statistically significant.

SNP 276G $>$ T exhibited lower plasma monounsaturated FA $(\Delta,-1.3 ; 95 \% \mathrm{CI},-2.46$ to -0.12$), \mathrm{C} 18: 3 n-3(\Delta,-0.07$; $95 \% \mathrm{CI},-0.11$ to -0.03$), \mathrm{C} 20: 5 n-3 / \mathrm{C} 20: 4 n-6(\Delta$, $-0.01 ; 95 \% \mathrm{CI},-0.02$ to -0.001$)$, and higher $n-6$ LCPUFA $(\Delta, 0.80 ; 95 \%$ CI, 0.18 to 1.42$)$ and C20:4n- $6(\Delta$, $0.66 ; 95 \%$ CI, 0.16 to 1.16 ). Children with SNP $276 \mathrm{G}>\mathrm{T}$ showed further lower plasma PL C18:3n - 3, C20:5n 3/C20:4n-6, and higher $n-6 / n-3$ LCPUFA (Table 2). No significant differences were found between carriers of $\mathrm{T}$ allele and noncarriers for total dietary energy or any macronutrient intake: mean (SD) total energy (kcal/die), 2420 (850) versus 2706 (880); protein (\%), 15.6 (2.4) versus 15.8 (3.3); carbohydrate (\%), 54.3 (6.3) versus 54.5 (7.3); fat (\%), 33.5 (5.0) versus 33.2 (5.1), as far as dietary intakes of the main FA families, including PUFAs (\%), 5.2 (1.5) versus 5.1 (1.7).

HOMA-IR was associated with plasma LCPUFAs profile, i.e. with polyunsaturated FA (Spearman correlation coefficient, $\rho,-0.222, p=0.024), \mathrm{C} 22: 6 n-3(-0.249, p=$ $0.011), n-6 / n-3$ PUFA $(0.232, p=0.018)$, and $n-6 / n-$ 3 LCPUFA $(0.266, p=0.007)$ in plasma phospholipids.

Table 3 shows the essential significant results from an ANOVA analysis including $\log _{10} \mathrm{HOMA}-\mathrm{IR}$ as dependent variable, SNP 276G $>$ T as factor, and LCPUFAs and confounders as covariates. This analysis showed a significant association of insulin resistance both with SNP 276G $>$ T and fatty acids per se and, additionally, a significant interaction between SNP 276G $>$ T and fatty acids.

\section{DISCUSSION}

This study examined the relationship of insulin resistance with adiponectin genotype SNP $276 \mathrm{G}>\mathrm{T}$ and plasma fatty acids in obese children. The estimated prevalence of SNP
Table 3. Significant results from ANOVA analysis including $\log _{10}$ HOMA-IR as dependent variable, SNP 276G $>$ T as factor, LCPUFAs and confounders* as covariates

\begin{tabular}{lcrcc}
\hline & $\begin{array}{c}\text { Type III } \\
\text { sum of squares }\end{array}$ & \multicolumn{1}{c}{$F$} & $p$ \\
\hline Without interactions & & & \\
$\quad$ Corrected model & $1.74 \dagger$ & 6.75 & $<0.0001 \ddagger$ \\
SNP 276G $>\mathrm{T}$ & 0.893 & 10.34 & $0.002 \ddagger$ \\
$\mathrm{n}-6 / \mathrm{n}-3$ LCPUFA & 0.365 & 4.25 & $0.042 \ddagger$ \\
Including interactions & & & \\
$\quad$ Corrected model & $2.24 \S$ & 5.47 & $<0.0001 \ddagger$ \\
$\quad$ SNP $276 \mathrm{G}>\mathrm{T} \times \mathrm{n}-6 / \mathrm{n}-3$ LCPUFA & 0.353 & 4.08 & $0.046 \ddagger$ \\
\hline
\end{tabular}

* Gender, age, body weight at birth, BMI $z$-score, duration of obesity and Tanner stage, plasma total cholesterol, and triacylglycerol concentrations. $\dagger r^{2}=0.182$ (adjusted $R^{2}=0.155$ ).

\$ Statistically significant.

$\S r^{2}=0.235$ (adjusted $R^{2}=0.192$ ).

$276 \mathrm{G}>\mathrm{T}$ was around $50 \%$, in agreement with previous studies $(10,13)$. Plasma total cholesterol and triacylglycerol levels did not differ between children with or not SNP $276 \mathrm{G}>\mathrm{T}$. Indeed, this result may be not unexpected in this study, as children with nonnormal blood lipid levels were excluded.

As a whole, an independent association was found between insulin resistance and SNP $276 \mathrm{G}>\mathrm{T}$. Indeed, children with the SNP 276G $>$ T exhibited higher values of fasting insulin and HOMA-IR, as observed also in adults (10-14). Other authors (16) did not find a significant association between insulin resistance and the SNP of the adiponectin gene analyzed in this study. However, it should be pointed out that children studied by Petrone et al. (16) showed a mean HOMA-IR of $\sim 5.2$, both in SNP $276 \mathrm{G}>\mathrm{T}$ carriers or noncarriers, compared with 4.5 and 2.6, respectively, found in this study. They showed further $\sim 24 \%$ higher mean BMI $z$-score ( 2.75 versus 
2.2), i.e. a more marked obesity. Accordingly, results by Petrone et al. (16) might be not directly comparable with the present findings, and no definitive conclusion can be therefore drawn.

In the present data, SNP $276 \mathrm{G}>\mathrm{T}$ carriers showed higher levels of $n-6 / n-3$ LCPUFA ratio and a lower C20:5n3/C20:4n- 6 ratio in plasma phospholipids than noncarriers. This result supports recent findings reporting that in obese children a higher BMI $z$-score may be associated with higher plasma levels of the $n-6 / n-3$ PUFA ratio (17). No dietary differences between carriers of SNP 276G $>\mathrm{T}$ and noncarriers were found, but caution should be paid because of the unfeasibility to estimate the dietary intake of the single Fat from the Italian Food Composition Tables. The potential relationship between plasma FAs values and dietary FAs intakes would be an important matter to be investigated. Also, it can be not excluded that a preferential channeling of dietary LCPUFAs and/or a minor LCPUFA endogenous synthesis from the parental $n-6$ and $n-3$ precursors might take place in obese children with SNP 276G $>$ T. Indeed, HOMA-IR was associated with a different LCPUFAs profile in plasma phospholipids. This result supports previous data showing that a higher $n-6 / n-3$ PUFA ratio in membrane muscles may occur in subjects with increased insulin resistance $(32,33)$. Whichever the case, as carriers of SNP 276G $>\mathrm{T}$ are at risk of metabolic complications (10-14), interventions aimed to improve the levels of LCPUFAs in membranes might be considered in these children, hopefully to benefit their insulin sensitivity.

Lastly, interestingly, an ANOVA analysis disclosed that an interaction of SNP 276G $>$ T and plasma fatty acids may exist. This may suggest that LCPUFAs may modulate the relationship of insulin resistance with the SNP 276G $>$ T. Further research needs to clarify this relevant question.

Large longitudinal studies are desirable to clarify the mutual relationships among metabolic conditions, adiponectin gene, and plasma LCPUFA in obese children and to assess whether dietary interventions might improve the metabolic conditions in carriers of the SNP $276 \mathrm{G}>\mathrm{T}$.

\section{REFERENCES}

1. DeFronzo RA, Bonadonna RC, Ferranini E 1992 Pathogenesis of NIDDM. A balanced overview. Diabetes Care 15:318-367

2. Sinha R, Fisch G, Teague B, Tamborlane WV, Banyas B, Allen K, Savoye M, Rieger V, Taksali S, Barbetta G, Sherwin RS, Caprio S 2002 Prevalence of impaired glucose tolerance among children and adolescents with marked obesity. N Engl J Med 346:802-810

3. Cali AM, Caprio S 2008 Obesity in children and adolescents. J Clin Endocrinol Metab 93:S31-S36

4. Saltiel AR 2000 The molecular and physiological basis of insulin resistance: emerging implications for metabolic and cardiovascular disease. J Clin Invest 106:163-164

5. Matsuzawa Y, Funahashi T, Nakamura T 1999 Molecular mechanism of metabolic syndrome $\mathrm{X}$ : contribution of adipocytokines adipocyte-derived bioactive substances. Ann N Y Acad Sci 892:146-154

6. Rasouli N, Kern PA 2008 Adipocytokines and the metabolic complications of obesity. J Clin Endocrinol Metab 93:S64-S73

7. Yamauchi T, Kadowaki T 2008 Physiological and pathophysiological roles of adiponectin and adiponectin receptors in the integrated regulation of metabolic and cardiovascular diseases. Int J Obes (Lond) 32:S13-S18
8. Savino F, Petrucci E, Nanni GE 2008 Adiponectin: an intriguing hormone for paediatricians. Acta Paediatr 97:701-705

9. Scherer PE, Williams S, Fogliano M, Baldini G, Lodish HF 1995 A novel serum protein similar to C1q, produced exclusively in adipocytes. J Biol Chem 270:2674626749

10. Hara K, Boutin P, Mori Y, Tobe K, Dina C, Yasuda K, Yamauchi T, Otabe S, Okada T, Eto K, Kadowaki H, Hagura R, Akanuma Y, Yazaki Y, Nagai R, Taniyama M, Matsubara K, Yoda M, Nakano Y, Tomita M, Kimura S, Ito C, Froguel P, Kadowaki T 2002 Genetic variation in the gene encoding adiponectin is associated with an increased risk of type 2 diabetes in the Japanese population. Diabetes 51:536-540

11. Shin MJ, Jang Y, Koh SJ, Chae JS, Kim OY, Lee JE, Ordovas JM, Lee JH 2006 The association of SNP $276 \mathrm{G}>\mathrm{T}$ at adiponectin gene with circulating adiponectin and insulin resistance in response to mild weight loss. Int J Obes (Lond) 30:1702-1708

12. Zacharova J, Chiasson JL, Laakso M 2005 The common polymorphisms (single nucleotide polymorphism [SNP] +45 and SNP +276 ) of the adiponectin gene predict the conversion from impaired glucose tolerance to type 2 diabetes: the STOP-NIDDM trial. Diabetes 54:893-899

13. Gonzalez-Sanchez JL, Zabena CA, Martınez-Larrad MT, Fernandez-Perez C, PerezBarba M, Laakso M, Serrano-Rios M 2005 An SNP in the adiponectin gene is associated with decreased serum adiponectin levels and risk for impaired glucose tolerance. Obes Res 13:807-812

14. Jang Y, Lee JH, Chae JS, Kim OY, Koh SJ, Kim JY, Cho H, Lee JE, Ordovas JM 2005 Association of the $276 \mathrm{G}>\mathrm{T}$ polymorphism of the adiponectin gene with cardiovascular disease risk factors in nondiabetic Koreans. Am J Clin Nutr 82:760767

15. Jang Y, Lee JH, Kim OY, Koh SJ, Chae JS, Woo JH, Cho H, Lee JE, Ordovas JM 2006 The SNP $276 \mathrm{G}>\mathrm{T}$ polymorphism in the adiponectin (ACDC) gene is more strongly associated with insulin resistance and cardiovascular disease risk than SNP $45 \mathrm{~T}>\mathrm{G}$ in nondiabetic Korean men independent of abdominal adiposity and circulating plasma adiponectin. Metabolism 55:59-66

16. Petrone A, Zavarella S, Caiazzo A, Leto G, Spoletini M, Potenziani S, Osborn J, Vania A, Buzzetti R 2006 The promoter region of the adiponectin gene is a determinant in modulating insulin sensitivity in childhood obesity. Obesity (Silver Spring) 14:1498-1504

17. Scaglioni S, Verduci E, Salvioni M, Bruzzese MG, Radaelli G, Zetterstrom R, Riva E, Agostoni C 2006 Plasma long-chain fatty acids and the degree of obesity in Italian children. Acta Paediatr 95:964-969

18. Flachs P, Mohamed-Ali V, Horakova O, Rossmeisl M, Hosseinzadeh-Attar MJ, Hensler M, Ruzickova J, Kopecky J 2006 Polyunsaturated fatty acids of marine origin induce adiponectin in mice fed a high-fat diet. Diabetologia 49:394-397

19. Nelson TL, Stevens JR, Hickey MS 2007 Adiponectin levels are reduced, independent of polymorphisms in the adiponectin gene, after supplementation with alphalinolenic acid among healthy adults. Metabolism 56:1209-1215

20. Italian Society for Paediatric Nutrition (SINUPE) 2000 Guidelines for the prevention of atherosclerosis in pediatric age. Riv Ital Pediatr 26:13-28

21. Decsi T, Koletzko B 1994 Fatty acid composition of plasma lipid classes in healthy subjects from birth to young adulthood. Eur J Pediatr 153:520-525

22. Cole TJ, Bellizzi MC, Flegal KM, Dietz WH 2000 Establishing a standard definition for child overweight and obesity worldwide: international survey. BMJ 320:12401243

23. Cacciari E, Milani S, Balsamo A, Dammacco F, De Luca F, Chiarelli F, Pasquino AM, Tonini G, Vanelli M 2002 Italian cross-sectional growth charts for height, weight and BMI (6-20 y). Eur J Clin Nutr 56:171-180

24. Cole TJ 1990 The LMS method for constructing normalized growth standards. Eur J Clin Nutr 44:45-60

25. Matthews DR, Hosker JP, Rudenski AS, Naylor BA, Treacher DF, Turner RC 1985 Homeostasis model assessment: insulin resistance and beta-cell function from fasting plasma glucose and insulin concentrations in man. Diabetologia 28:412-419

26. Friedewald WT, Levy RI, Frederickson DS 1972 Estimation of the concentration of low-density lipoprotein in plasma, without use of preparative ultracentrifuge. Clin Chem 18:499-502

27. Folch J, Lees M, Sloane-Stanley GH 1956 A simple method for isolation of total lipids from human tissues. J Biol Chem 226:497-509

28. Agostoni C, Trojan S, Bellu R, Riva E, Giovannini M 1995 Neurodevelopmental quotient of healthy term infants at 4 months and feeding practice: the role of long-chain polyunsaturated fatty acids. Pediatr Res 38:262-266

29. Rosner B, Prineas RJ, Loggie JM, Daniels SR 1993 Blood pressure nomograms for children and adolescents by height, sex, and age, in the United States. J Pediatr 123:871-886

30. Block G, Hartman AM, Dresser CM, Carroll MD, Gannon J, Gardner L 1986 A data-based approach to diet questionnaire design and testing. Am J Epidemiol 124:453-469

31. Istituto Nazionale della Nutrizione (Italian Institute of Nutrition) 1997 Food Composition Tables. Istituto Nazionale della Nutrizione, Rome, pp 16-80

32. Borkman M, Storlien LH, Pan DA, Jenkins AB, Chisholm DJ, Campbell LV 1993 The relation between insulin sensitivity and the fatty-acid composition of skeletalmuscle phospholipids. N Engl J Med 328:238-244

33. Storlien LH, Pan DA, Kriketos AD, O'Connor ID, Cooney GJ, Jenkins AB, Baur LA 1996 Skeletal muscle membrane lipids and insulin resistance. Lipids 31:S261-S265 